\title{
The Impact of Public R \& D Subsidies on Private R \& D Expenditure and Its Innovation Performance-An Empirical Study Based on Industrial Enterprises in Guangdong Province
}

\author{
Jingwen Xia, Yi Zhu \\ Department of International and Economics, School of Economics, Jinan University, Guangzhou, China \\ Email: judychuh21@163.com
}

How to cite this paper: Xia, J.W. and Zhu, Y. (2019) The Impact of Public R \& D Subsidies on Private R \& D Expenditure and Its Innovation Performance-An Empirical Study Based on Industrial Enterprises in Guangdong Province. Modern Economy, 10, 261-280.

https://doi.org/10.4236/me.2019.101018

Received: December 26, 2018

Accepted: January 19, 2019

Published: January 22, 2019

Copyright $\odot 2019$ by author(s) and Scientific Research Publishing Inc. This work is licensed under the Creative Commons Attribution International License (CC BY 4.0).

http://creativecommons.org/licenses/by/4.0/

\begin{abstract}
Based on the panel data of Guangdong industrial enterprises from 2006 to 2013, this paper empirically studies the impact of public R \& D subsidies on private $\mathrm{R} \& \mathrm{D}$ expenditure and the impact of the two on the innovation performance of enterprises by using random effects model and fixed effects model. The results show that public $\mathrm{R} \& \mathrm{D}$ subsidies can promote enterprises to carry out private $\mathrm{R} \& \mathrm{D}$ expenditure, and there is an obvious time lag. Using grouping studies, we found that low-level public R \& D subsidies can encourage enterprises to increase their private $\mathrm{R} \& \mathrm{D}$ expenditure, but high-level public subsidies will crowd out part of private R \& D expenditure. Finally, this paper divides the innovation performance of enterprises into the stage of knowledge output and the stage of marketization. In the knowledge output stage, public R \& D subsidies and R \& D staff input can significantly improve the innovation performance of enterprises; in the marketization stage, public $\mathrm{R} \& \mathrm{D}$ subsidies cannot promote the increase of new product income, while the private $\mathrm{R} \& \mathrm{D}$ expenditure of enterprises can significantly increase the income of new products.
\end{abstract}

\section{Keywords}

Public R \& D Subsidies, Industrial Enterprises, Private R \& D Expenditure, Innovation Performance

\section{Introduction}

Today, with economic globalization and increasingly fierce technological competition, the impact of technological innovation on economic growth is increa- 
singly prominent, and it is the most important support for realizing economic growth and industrial upgrading in a country and region. Scientific and technological innovation and scientific research achievements mainly come from scientific research institutions and universities, but more from technical research and development of industrial enterprises. Industrial enterprises continue to provide advanced technical equipment for all sectors of the national economy, ensuring the continuous development of production of various sectors on the base of advanced technology, thus driving the modernization of the entire economy, which is an important pillar of the national economy. Therefore, the innovation of industrial enterprises is crucial to the development of the national economy. It is the foundation of technological innovation and the hub of innovation and development in other industries.

The technological innovation and R \& D achievements have the externality of public goods. The enterprises conducting R \& D cannot fully enjoy the benefits brought by $\mathrm{R} \& \mathrm{D}$ investment, which suppresses the enthusiasm of enterprises for R \& D investment, which leads to the lack of $\mathrm{R} \& \mathrm{D}$ investment. The government's grant of $\mathrm{R} \& \mathrm{D}$ subsidies to enterprises is the most effective public policy to correct this externality. The internalization of externalities can reduce the cost and risk of innovation for technological innovation; but it may also crowd out private R \& D expenditure. Although public R \& D subsidies and private $\mathrm{R} \& \mathrm{D}$ expenditure are increasing day by day, the interrelationships between them are still widely discussed. It has always been a topic of discussion among scholars at home and abroad. This issue is widespread in the world and China, and it is necessary to pay full attention to it.

In October 2018, the "Guangdong Provincial Regional Innovation Capability Evaluation Report" issued by Guangdong Institute of Scientific and Technical Information concluded that the regional innovation capacity of Guangdong Province ranked first in China in 2017, pointing out that the level of R \& D investment in Guangdong Province has been continuously improved in recent years. First, the intensity of R \& D investment continues to increase. In 2016, the province's $\mathrm{R} \& \mathrm{D}$ intensity ( $\mathrm{R} \& \mathrm{D}$ expenditure as a percentage of GDP) was about $2.56 \%$, higher than the national average $(2.08 \%)$. Second, the patent output is leading the country. The total number of patent applications accepted in the year was 505,667 , an increase of $42.1 \%$; the total number of patent authorizations for the year was 259,032 , an increase of $7.4 \%$, ranking first in the country. Third, high-tech enterprises have steadily improved. In 2016, there were a total of 19,857 high-tech enterprises in the province, an increase of 8752 over 2015, an increase of $78.8 \%$; the output value of high-tech products was 6.1 trillion yuan, an increase of $13.0 \%$. Fourth, the carrier of innovation and entrepreneurship is continuously enriched. In recent years, Guangdong R \& D has invested heavily in industrial enterprises above designated size. The investment in $\mathrm{R} \& \mathrm{D}$ of industrial enterprises in Guangdong Province has continued to grow rapidly. In 2016, the R \& D expenditure of industrial enterprises in the province was 
167.627 billion yuan, an increase of $10.2 \%$, accounting for the province's research and development funds. $82.4 \%$ of the input. However, Guangdong still has many weak links in the original innovation and the transformation of achievements. The innovation motivation is insufficient, the innovation performance is not ideal, and the government and enterprises must work together to continue to improve innovation to drive development. (The above data comes from the "Guangdong Provincial Regional Innovation Capability Evaluation Report" issued by Guangdong Institute of Scientific and Technical Information.)

Therefore, it is important to understand the relationship between the R \& D investment of the Guangdong Provincial Government and the private R \& D expenditure of industrial enterprises and the impact and effectiveness of the two on the innovation performance of enterprises. This paper takes Guangdong large and medium-sized industrial enterprises as the research sample, uses the industry panel data of 20 industrial enterprises in Guangdong Province from 2006 to 2013, and uses the knowledge production function as a model to study the impact of public $\mathrm{R} \& \mathrm{D}$ subsidies on private $\mathrm{R} \& \mathrm{D}$ expenditure and its innovation performance. It is hoped that through this research, the government can conduct more reasonable and effective $\mathrm{R} \& \mathrm{D}$ fund allocation for industrial enterprises, and guide industrial enterprises to conduct R \& D through R \& D subsidies, thereby driving other industries to carry out technological innovation, improve the conversion rate of scientific and technological achievements, and improve the innovation performance of the whole industry.

\section{Literature Review}

In 1956, Solow [1] (Solow) discussed the important role of technological innovation in economic growth, and this issue was gradually taken seriously. Since the 1980s, endogenous growth theory has become an important area of macroeconomic research, the relationship between technological innovation and economic growth began to be focused on. The government began to increase its attention and funding for corporate innovation, and domestic and foreign scholars began to study the relationship between the two. At present, the research on government $\mathrm{R} \& \mathrm{D}$ subsidies is mainly divided into two types. The first category mainly studies the impact of public $R \& D$ subsidies on private $R$ \& D expenditure of enterprises-the extrusion effect or the incentive effect. The second type studies the impact of $\mathrm{R} \& \mathrm{D}$ subsidies on innovation performance of industrial enterprises.

Lach, Saul [2] and Guellec, D [3] measure out the relevant government departments' subsidies stimulated the development of the company's R \& D expenditure, the latter found that the effectiveness of corporate $\mathrm{R} \& \mathrm{D}$ investment in the form of an inverted U shape; Marianna Marino, Stephane Lhuillery [4] and Lvjiu Qin, Yu Dandan [5], who verified the public R \& D subsidies will crowd out innovative $\mathrm{R} \& \mathrm{D}$ investment. Most studies have demonstrated that public R \& D subsidies has different effects on different types of enterprises and 
types of enterprises of different scales by controlling different variables. For example, Yang Yan, Wang Peng [6] found that for Chinese listed companies, public subsidies have a positive effect on corporate performance, but the form of direct public subsidies has a negative adjustment effect. Zhang Jie, Chen Zhiyuan [7] found that in areas where the intellectual property protection system is weaker, the government's innovative subsidy policy can promote the private R \& $\mathrm{D}$ of enterprises; the government subsidy policy of loan interest subsidy type has caused significant squeeze on private R \& D.

Regardless of whether government subsidies have squeezed out the company's private $\mathrm{R} \& \mathrm{D}$ expenditure, its impact on corporate innovation performance cannot be ignored. The empirical results of most literatures prove that government subsidies can promote the innovation performance of enterprises. Matthias Almus, Dirk Czarnitzki [8] believes that the innovation activity of Eastern German companies has increased by about 4 percentage points compared to the absence of public financial means. Xiaolu Liu, Xiaoyu Li [9] found that public R \& $\mathrm{D}$ subsidies significantly stimulated private $\mathrm{R} \& \mathrm{D}$ expenditure, and the smaller the company size and the more limited the funds, the more effective the $\mathrm{R} \& \mathrm{D}$ subsidies. Sun Zao, Song Wei [10] proved that the positive correlation between private enterprise $\mathrm{R} \& \mathrm{D}$ investment and industrial innovation performance is more significant through the research on China's manufacturing panel data. $\mathrm{Lu}$ Guoqing, Zhou Wang, Zhang Chunyu [11] obtained government performance on strategic emerging generate innovation subsidies is significant. In addition, some literatures have carried out more detailed research based on the former. Wang Jun [12] measured the output elasticity of government R \& D subsidies and China's 28 manufacturing, pointing out that government R \& D subsidies should inputs more subsidies on high-tech companies with good prospects. An Tongliang, Zhou Shaodong, Pi Jiancai [13] established a dynamic asymmetric information game model between enterprises and R \& D subsidy policy makers, and found that there is information asymmetry between the two. And when the human capital price used for original innovation is too low, the original innovation subsidy will produce a reverse incentive. An Tongliang, Ludovico Alcorta [14] revealed in another article that there is a clear oblique V-shaped structural relationship between $\mathrm{R} \& \mathrm{D}$ intensity trends of small companies, medium-sized companies and large companies in China. Liu Hong, XiaoMeifeng, Tang Qingquan [15] through research on government subsidies under different political environments and enterprises, it is concluded that government R \& D subsidies will have incentive effects and crowding out effects on enterprises. The distribution of the two effects is inverted U-shaped, and the political environment in which the enterprises are located the worse, the weaker the anti-corruption, the less significant the effect of $\mathrm{R} \& \mathrm{D}$ subsidies, and vice versa.

Impact of public $\mathrm{R} \& \mathrm{D}$ subsidies for private $\mathrm{R} \& \mathrm{D}$ expenditure and innovation performance has not been consistent results, the results of empirical analysis due to business, industry, region to region, selected samples and different 
models may come to different conclusions. Therefore, this paper combines two research types and attempts to analyze the impact of Guangdong government $\mathrm{R}$ \& D subsidies on the private R \& D expenditure and innovation performance of large and medium-sized industrial enterprises from an empirical perspective, and use the panel data of Guangdong industrial enterprises from 2006 to 2013 to investigate the relationship between the public R \& D subsidies and private R \& $\mathrm{D}$ expenditure and whether public subsidies can promote enterprises to increase R \& D expenditure spontaneously, and examine the role of public subsidies and private expenditure on innovation performance, whether they have an impact on innovation output, and the impact of different sources of capital and human resources on innovation output efficiency.

\section{Model Setting and Data Processing}

This paper selects Guangdong Province with relatively complete scientific and technological data as the research object, and analyzes the panel data of 20 industries in Guangdong Province from 2006 to 2013. Model 1 is used to measure the incentive effect of public $\mathrm{R} \& \mathrm{D}$ subsidies on private $\mathrm{R} \& \mathrm{D}$ expenditure. Model 2 mainly measures the impact of public and private R \& D investment on enterprise innovation performance. Through these two models, we can estimate the relationship between the two main subsidies and their respective impact on the innovation performance of the enterprise. The strength of the two subsidies can be adjusted according to the research results to maximize the $\mathrm{R} \& \mathrm{D}$ performance of the enterprise.

\subsection{Model Setting}

\subsubsection{Model 1}

Considering the relationship between public $\mathrm{R} \& \mathrm{D}$ subsidies and private $\mathrm{R} \& \mathrm{D}$ expenditure is complicated, this paper makes a general analysis of the role of $\mathrm{R} \&$ $\mathrm{D}$ funds and annual profit of industrial enterprises raised from different sources on the independent R \& D investment of enterprises, and sets the relationship between them as a general linear function. Among them, the enterprise private $\mathrm{R}$ \& D expenditure (ERD) as the explained variable, the government public $\mathrm{R} \& \mathrm{D}$ subsidies (GRD) as an explanatory variable, and the financial institution loan $(\mathrm{FL})$, overseas fund $(\mathrm{OF})$, enterprise annual profit (EP) three different funds source as a control variable, build the following model:

$$
\mathrm{ERD}_{i, t}=\alpha \mathrm{GRD}_{i, t}+\beta \mathrm{FL}_{i, t}+\delta \mathrm{OF}_{i, t}+\varepsilon \mathrm{EP}_{i, t}+\gamma_{i}+\epsilon_{i, t}
$$

Table 1 shows the meaning, abbreviations, and units of variables.

In addition, $\gamma_{i}$ is a random error term that reflects the industry difference, and $\epsilon_{i, t}$ reflects the mixed difference between the industry and time.

\subsubsection{Model 2}

In the existing literature on measuring innovation performance, the knowledge production function is usually established with the extended Cobb-Douglas 
Table 1. The meaning of the variables of model 1.

\begin{tabular}{cccc}
\hline & Variable & Abbreviation & Unit \\
\hline explained variable & enterprise private R \& D expenditure & ERD & \\
explanatory variable & government public R \& D subsidies & GRD & \\
& financial institution loans & FL & ten thousand \\
control variable & overseas funds & OF & \\
& enterprise annual profit & EP & \\
\hline
\end{tabular}

knowledge production function as the basic model. The input of this function is expressed by R \& D capital and personnel, and the innovation performance is expressed by the number of patents and the sales revenue of new products, the form is as follows:

$$
Y_{i t}=A K_{i t}^{\beta} L_{i t}^{\gamma} X_{i t}^{\delta} e_{i t}^{\epsilon}
$$

Among them, $Y$ represents the innovation output of the enterprise, $A$ is a constant, $K$ represents the $\mathrm{R} \& \mathrm{D}$ investment of the enterprise, $L$ represents the input of the enterprise R \& D personnel, $X$ represents other control variables, and $\beta$ and $\gamma$ are random error terms, which represent the output elasticity of $\mathrm{R} \&$ $\mathrm{D}$ capital and personnel, and indicate the degree of influence of each control variable on innovation performance. Based on formula (2), this paper divides R \& D capital investment into government input (GRD) and enterprise input (ERD), and performs logarithm processing. Finally, the following formula is obtained:

$$
\ln Y_{i, t}=\beta_{1} \ln \mathrm{ERD}_{i, t}+\beta_{2} \ln \mathrm{GRD}_{i, t}+\gamma \ln L_{i, t}+\delta_{1} \ln \mathrm{FL}_{i, t}+\delta_{2} \ln \mathrm{OF}_{i, t}+\epsilon_{i, t}
$$

Table 2 shows the meaning of the variables.

\subsection{Data Collection and Descriptive Statistics}

The data in this paper comes from the industry data of large and medium-sized industrial enterprises in the 2006-2013 Guangdong Science and Technology Statistical Yearbook. During the inspection period, the industrial statistics catalogue of industrial enterprises changed. Before 2007, it was 20 industries, and 2008, 2010, 2011 were subdivided into 33 industries, there were 35 industries in 2009, 34 industries in 2012, and 44 industries in 2013. To ensure the consistency of the research caliber, this paper excludes some sub-sectors and uses the 20 industries in 2006 as the standard for statistics. Data were collected from five parts: the basic situation of industrial enterprises, $R \& D$ activity fund raising data, $R \& D$ activities personnel, technology projects and patents, and new product development, production and sales. Among them, from 2006 to 2008, only the proportion of sales revenue of new products to the main business was given. From 2009 to 2013, the sales revenue of new products was directly given. Therefore, the value from 2006 to 2008 is calculated.

Table 3 gives descriptive statistical characteristics of the explained, explanatory, and control variables. The overall quality of the data is good and there are no extreme abnormal values, which is suitable for the next analysis. 
Table 2. The meaning of the variables of model 2.

\begin{tabular}{|c|c|c|c|c|}
\hline & Variable & Abbreviation & Unit & Calculation method \\
\hline \multirow{2}{*}{$\begin{array}{l}\text { explained } \\
\text { variable }\end{array}$} & \multirow{2}{*}{$\begin{array}{l}\text { enterprise innovation } \\
\text { performance }\end{array}$} & $P$ & PCS & $\begin{array}{l}\text { the number of patent } \\
\text { applications }\end{array}$ \\
\hline & & $Y$ & \multirow{5}{*}{$\begin{array}{l}\text { ten thousand } \\
\text { yuan }\end{array}$} & New product sales revenue \\
\hline \multirow{2}{*}{$\begin{array}{l}\text { explanatory } \\
\text { variable }\end{array}$} & $\begin{array}{l}\text { enterprise private } \mathrm{R} \& \mathrm{D} \\
\text { expenditure }\end{array}$ & ERD & & 1 \\
\hline & $\begin{array}{c}\text { government public R \& D } \\
\text { subsidies }\end{array}$ & GRD & & 1 \\
\hline \multirow{3}{*}{ control variable } & financial institution loans & FL & & 1 \\
\hline & overseas funds & OF & & 1 \\
\hline & $\begin{array}{l}\text { the input of the enterprise } \\
\text { R \& D personnel }\end{array}$ & $L$ & person & $\begin{array}{l}\mathrm{R} \& \mathrm{D} \text { personnel equivalent } \\
\text { to full-time equivalent }\end{array}$ \\
\hline
\end{tabular}

Table 3. Descriptive statistics for each variable.

\begin{tabular}{cccccc}
\hline Variable & Sample size & Mean & Standard deviation & Min. & Max. \\
\hline EP & 160 & $7,612,247$ & $17,600,000$ & $49,533.7$ & $133,825,908.6$ \\
$P$ & 160 & 2749.287 & 7391.972 & 2 & 41,540 \\
$Y$ & 160 & $5,046,876$ & $1.30 \mathrm{e}+07$ & 0 & $9.13 \mathrm{e}+07$ \\
ERD & 160 & 337,003 & $80,0130.7$ & 1811 & $5,626,542$ \\
GRD & 160 & $10,208.65$ & $25,031.98$ & 0 & $186,263.1$ \\
FL & 160 & 5860.711 & $12,539.33$ & 0 & $83,465.4$ \\
OF & 160 & 4189.747 & $16,445.7$ & 0 & $140,571.4$ \\
$L$ & 160 & $12,758.24$ & $30,596.41$ & 28 & $194,615.4$ \\
\hline
\end{tabular}

Notes: The data is compiled according to the 2006-2013Guangdong Science and Technology Statistical Yearbook.

\section{The Impact of Public R \& D Subsidies on Private R \& D Expenditure-Additionality or Crowding-Out?}

Enterprise R \& D expenditures are divided into internal funds and external funds. External funds include government R \& D subsidies, financial institution loans and overseas funds. This part regards the enterprise's private R \& D expenditure as a function of government public $\mathrm{R} \& \mathrm{D}$ subsidies, financial institution loans, overseas funds and total annual profit of the enterprise. The private $\mathrm{R}$ \& $\mathrm{D}$ expenditure of the enterprise is taken as the explained variable, the public $\mathrm{R}$ \& D subsidies is taken as the explanatory variable, and add the financial institution loans, overseas funds, corporate annual interest rate and other control variables, build the following model:

$$
\mathrm{ERD}_{i, t}=\alpha \mathrm{GRD}_{i, t}+\beta \mathrm{FL}_{i, t}+\delta \mathrm{OF}_{i, t}+\varepsilon \mathrm{EP}_{i, t}+\gamma_{i}+\epsilon_{i, t}
$$

The commonly used estimation methods for panel data are least squares estimation, fixed effect model and random effect model. The data in this paper are short panel data. The least squares estimation, fixed effect regression and ran- 
dom effect regression are performed on the above models by using Stata12.0 software.

Table 4 gives the results of the model by using Stata 12.0 software.

\subsection{Overall Regression Analysis}

\subsubsection{Comparative Analysis of FE and RE}

The results of fixed-effect analysis using Stata12.0 software showed that $\mathrm{F}$ test that all $\mathrm{u}_{-} \mathrm{i}=0, \mathrm{~F}(19,136)=10.17$, Prob $>\mathrm{F}=0.0000$, significantly rejecting the null hypothesis that each sample does not have its own intercept term, so it can be preliminarily judged that each individual has different intercept terms, and the fixed effect model is superior to the ordinary least squares regression model.

\subsubsection{Hausman Test}

The Hausman test was used to compare and analyze the fixed effects model and the random effects model. The null hypothesis of the Hausman test is to use a random effects model. The results of the Hausman test: Prob $>$ chi $2=0.0000, \mathrm{P}$ value is much lower than 0.05 (see the figure below), rejecting the null hypothesis that the random effects model should be used, so the model is more reasonable to use a fixed effects model.

\subsubsection{Analysis of Regression Results of Fixed Effect Models}

In summary, this paper should construct a fixed effects model to analyze the regression relationship between public $\mathrm{R} \& \mathrm{D}$ subsidies and private $\mathrm{R} \& \mathrm{D}$ expenditure. The fixed effects model estimation results show that the model has an $\mathrm{F}$ value of 474.46 and a significant $P$ value of 0.0000 , the model is very significant overall. The R-square within group of the model is 0.9331 (within $=0.9331$ ), that is, the change ratio explained in the unit is $93.31 \%$; the R-square between group of the model is 0.9831 (between $=0.9831$ ); the overall $\mathrm{R}$-square of the model is 0.9683 (overall $=0.9683$ ), indicating that the explanatory power of the model is very strong.

Table 4. The impact of public $\mathrm{R} \& \mathrm{D}$ subsidies on private $\mathrm{R} \& \mathrm{D}$ expenditure.

\begin{tabular}{cccc}
\hline Variable & OLS & FE & RE \\
\hline GRD & $29.71^{* * *}$ & $26.13^{* * *}$ & $29.82^{* * *}$ \\
& $(0.546)$ & $(0.816)$ & $(0.532)$ \\
FL & $3.153^{* * *}$ & 1.223 & $2.072^{\star}$ \\
& $(1.115)$ & $(0.935)$ & $(1.059)$ \\
OF & 0.557 & $-1.546^{* *}$ & 0.0992 \\
& $(0.792)$ & $(0.602)$ & $(0.692)$ \\
EP & $0.00439^{* * *}$ & 0.000839 & $0.00430^{* * *}$ \\
& $(0.000773)$ & $(0.000897)$ & $(0.000735)$ \\
Constant & $-20.494^{*}$ & $63.139^{* * *}$ & -12.654 \\
& $(11.100)$ & $(15.079)$ & $(13.948)$ \\
R-squared & 0.977 & 0.933 & - \\
F & 1649.55 & 474.46 & - \\
\hline
\end{tabular}

Notes: The number in parentheses in the above table is the standard deviation of the estimated coefficients, $* * *, * *$, and ${ }^{*}$ indicate significant at the $1 \%, 5 \%$, and $10 \%$ levels. 
Observing the significant $P$ value of each variable coefficient in the model, the impact of public R \& D subsidies on the private R \& D expenditure of the enterprise is significantly positively correlated at the level of $1 \%$, indicating that for every 10,000 yuan increase in public $\mathrm{R} \& \mathrm{D}$ subsidies, the industrial enterprise will increase by 261,300 yuan's private R \& D expenditure. This result shows that the government's public R \& D subsidies have a strong incentive effect for industrial enterprises in Guangdong Province. The coefficient of loans from financial institutions is positive, but not significant, indicating that loans from financial institutions can increase their R \& D expenditures; and the impact of overseas funding on private $\mathrm{R} \& \mathrm{D}$ expenditure is significantly negatively correlated at $5 \%$. Increasing the loan input from overseas funds will reduce the company's private $\mathrm{R} \& \mathrm{D}$ expenditure. This may be because the repayment pressure of overseas funds is relatively large, and enterprises are afraid to use this part of the funds for R \& D. R \& D is a phased activity, if overseas channels urge repayment, the funds invested by enterprises in $\mathrm{R} \& \mathrm{D}$ activities cannot be recovered at once. Since the competitive advantage is reflected in the profit, the enterprise must consider the profit it can bring to the enterprise when it engages in R \& D activities, so the enterprise profit is an important factor affecting the private $\mathrm{R} \& \mathrm{D}$ expenditures of the enterprise. The empirical results show that the total profit of industrial enterprises has a slight promotion effect on the independent $\mathrm{R} \& \mathrm{D}$ investment of the enterprise, but the result is not significant, indicating that the increase of corporate profits will increase the R \& D expenditures accordingly, but it has little effect on the $\mathrm{R} \& \mathrm{D}$. From the above analysis results, we can get the fitting equation of the fixed effect model:

$$
\mathrm{ERD}_{i, t}=26.13 \mathrm{GRD}_{i, t}+1.223 \mathrm{FL}_{i, t}-1.546 \mathrm{OF}_{i, t}+0.000839 \mathrm{EP}_{i, t}+63.139
$$

\subsection{Hysteresis Analysis}

Among the above four R \& D external funding sources, only the results of the two subsidies are significant. To test whether the incentive effect of subsidies is in time difference, this paper makes a lag analysis on the above variables.

Table 5 reflects the delay structure of the determinants of private $R \& D$ investment.

Table 5. Delay structure affecting the factors of private R \& D expenditure.

\begin{tabular}{ccccc}
\hline & GRD & FL & OF & EP \\
\hline $\mathrm{T}$ & $5.033^{\star *}$ & 0.466 & 0.0954 & $0.00395^{\star * *}$ \\
& $(2.172)$ & $(0.647)$ & $(0.800)$ & $(0.000724)$ \\
$\mathrm{T}-1$ & $6.580^{* * *}$ & 0.307 & -0.970 & $-0.00251^{\star * *}$ \\
& $(2.085)$ & $(0.639)$ & $(0.596)$ & $(0.000834)$ \\
$\mathrm{T}-2$ & $12.34^{\star * *}$ & 0.265 & $2.337^{\star * *}$ & $-0.00370^{\star * *}$ \\
& $(2.244)$ & $(0.622)$ & $(0.868)$ & $(0.000814)$ \\
\hline
\end{tabular}

Notes: The above table is an estimate of 160 observations (due to lag, observations reduced from 160 to 120) for 20 industry data from 2006 to $2013 .{ }^{* *}$, ${ }^{* *}$, and ${ }^{*}$ indicate significant levels at $1 \%, 5 \%$, and $10 \%$, and the values in pa-rentheses is t-test values. 
The results show that the total annual profit of the enterprise has a positive effect on the independent $\mathrm{R} \& \mathrm{D}$ investment of the enterprise. Its elasticity is about 0.00395 , but the corporate profits that lag the first phase and the second phase have a negative effect on the private $\mathrm{R} \& \mathrm{D}$ expenditure of the enterprise. In other words, the profit factor is indeed considered when the company conducts $\mathrm{R} \& \mathrm{D}$ investment, but the company may only withdraw funds from the current profits into the $\mathrm{R} \& \mathrm{D}$ activities. Lagging the profits of the first and second periods will reduce the current $\mathrm{R} \& \mathrm{D}$ expenditure. This may be because the corporate profits are the performance of the marketization of $\mathrm{R} \& \mathrm{D}$ results. If the profits of the first phase are increased, the company will increase the expenditure to produce the patent results that lag the first phase. It is often overlooked for the next phase of R \& D activities because of current profits. At the same time, the results also show that the impact of financial institution loans on the private $\mathrm{R} \& \mathrm{D}$ expenditure of enterprises is positive, although the results are not significant, but can promote the private R \& D expenditure to a certain extent, there is no obvious time lag effect. Funds from overseas can also promote private R \& D expenditure of enterprises. Although it shows a certain substitution effect in the first phase of lag, after two periods of lag, overseas funds have begun to exert obvious driving force on private $\mathrm{R} \& \mathrm{D}$ expenditure. This shows that the two-phase offshore investment can have a significant positive impact on the company's private R \& D expenditure. This time lag effect may be due to the uncertainty of the availability of funds, or it may be that the company can safely invest the funds in RR \& D activities after determining its repayment ability.

Most importantly, the government's R \& D subsidies as a major policy tool has a significant impact on private $\mathrm{R} \& \mathrm{D}$ expenditure. The public R \& D subsidies is significant for the current private $\mathrm{R} \& \mathrm{D}$ expenditure of enterprises at the level of $5 \%$. After the first and second periods, the private investment of enterprises has shown a strong promotion effect, which is significant at the level of $1 \%$. It shows that the public $\mathrm{R} \& \mathrm{D}$ subsidies increase with the increase of the year, and the coefficient is also increasing. The multiplier effect in the T-2 period reaches 12.34. The time-lag structure reflects that the leverage effect of public $\mathrm{R}$ \& D subsidies on the private R \& D expenditure needs a certain period to show, and it takes a certain time for enterprises to digest and use government subsidies, which is consistent with the characteristics of the slow knowledge spillover effect. The reason for the slow effect of government subsidies may also be that it takes a while for the subsidies funds to be transferred from the appropriation to the actual implementation of the industrial enterprises. This may affect the planning of private $\mathrm{R} \& \mathrm{D}$ expenditure in the year, and some enterprises will use the public subsidies that have not been used in the previous period to be used in the current period, which resulting in a lag effect.

Although the time-lag structure of variables varies, but $\mathrm{R} \& \mathrm{D}$ inputs from different sources can promote private $\mathrm{R} \& \mathrm{D}$ expenditure. Therefore, in the long run, providing convenient financing channels for enterprises and actively utiliz- 
ing overseas funds can promote enterprises to increase their private R \& D expenditure.

\subsection{Group Static Estimation}

To carefully analyze the incentive effect of public R \& D subsidies on industrial enterprises' private $\mathrm{R} \& \mathrm{D}$ expenditure, this paper divides the sample of existing public R \& D subsidies into four groups according to the government subsidy intensity. Calculated as follows:

$$
\text { public R\&D subsidies rate }=\frac{\text { public } R \& D \text { subsidies }}{\text { All R\&D investment of the enterprise }} \times 100 \%
$$

According to the Stata group processing, the government $\mathrm{R} \& \mathrm{D}$ subsidies rate is $3.7 \%$ higher than the high subsidies rate, $2.5 \%$ or more and less than $3.7 \%$ is the medium-high subsidies rate, $1.4 \%$ or more and less than $2.5 \%$ is the medium-low subsidies rate, less than $1.4 \%$ is low subsidies rate. Fixed-effect regression analysis was performed on the following four sets of data.

$$
\text { public R\&D subsidies rate }=\left\{\begin{array}{l}
<1.4 \%, \text { low piblic subsidies rate } \\
1.4 \% \sim 2.5 \%, \text { medium-low subsidies rate } \\
2.5 \% \sim 3.7 \%, \text { medium-high subsidies rate } \\
>3.7 \% \text {, high subsidies rate }
\end{array}\right.
$$

Table 6 shows the largest multiplier comes from the sample of the low public subsidies rate group, which is 40.24 , but the coefficient is not significant, indicating that the lower public $\mathrm{R} \& \mathrm{D}$ subsidies can promote industrial enterprises to carry out more private R \& D expenditure. The sample of the low- and medium-high public subsidies rate group showed significant high multiplier effects,

\begin{tabular}{|c|c|c|c|c|c|}
\hline & $\begin{array}{l}\text { Low subsidies } \\
\text { rate }\end{array}$ & $\begin{array}{l}\text { Medium-low } \\
\text { subsidies rate }\end{array}$ & $\begin{array}{l}\text { Medium-high } \\
\text { subsidies rate }\end{array}$ & $\begin{array}{l}\text { High subsidies } \\
\text { rate }\end{array}$ & $\begin{array}{c}\text { Add squared } \\
\text { term GRD }{ }^{2}\end{array}$ \\
\hline GRD & $\begin{array}{c}40.24 \\
(27.15)\end{array}$ & $\begin{array}{l}24.41^{\star * *} \\
(1.947)\end{array}$ & $\begin{array}{c}28.45^{\star * *} \\
(1.448)\end{array}$ & $\begin{array}{c}10.88^{\star * *} \\
(0.926)\end{array}$ & $\begin{array}{l}17.74^{* * *} \\
(1.520)\end{array}$ \\
\hline FL & $\begin{array}{l}-0.653 \\
(0.665)\end{array}$ & $\begin{array}{l}5.218^{\star *} \\
(1.864)\end{array}$ & $\begin{array}{l}13.32^{\star *} \\
(5.917)\end{array}$ & $\begin{array}{c}0.854 \\
(1.844)\end{array}$ & $\begin{array}{c}0.425 \\
(0.836)\end{array}$ \\
\hline OF & $\begin{array}{c}7.758 \\
(29.95)\end{array}$ & $\begin{array}{l}-0.316 \\
(1.446)\end{array}$ & $\begin{array}{l}-1.374^{*} \\
(0.692)\end{array}$ & $\begin{array}{l}11.04^{* * *} \\
(1.636)\end{array}$ & $\begin{array}{l}-0.745 \\
(0.547)\end{array}$ \\
\hline EP & $\begin{array}{c}-7.32 \mathrm{e}-05 \\
(0.00227)\end{array}$ & $\begin{array}{l}-0.00303 \\
(0.00179)\end{array}$ & $\begin{array}{l}-0.00396 \\
(0.00295)\end{array}$ & $\begin{array}{c}-0.00483^{* *} \\
(0.00179)\end{array}$ & $\begin{array}{c}0.00121 \\
(0.000794)\end{array}$ \\
\hline Constant & $\begin{array}{l}59,567^{\star *} \\
(24,864)\end{array}$ & $\begin{array}{c}155,510^{\star * *} \\
(20,868)\end{array}$ & $\begin{array}{c}43,568 \\
(41,522)\end{array}$ & $\begin{array}{c}45,292^{\star * *} \\
(10,624)\end{array}$ & $\begin{array}{c}115,901^{\star * *} \\
(15,751)\end{array}$ \\
\hline $\mathrm{GRD}^{2}$ & - & - & - & - & $\begin{array}{c}4.33 e-05^{\star * *} \\
(6.90 e-06)\end{array}$ \\
\hline Observations & 40 & 40 & 40 & 40 & 160 \\
\hline R-squared & 0.097 & 0.888 & 0.983 & 0.949 & 0.948 \\
\hline
\end{tabular}

Table 6. Impact of different government subsidy rates on private R \& D expenditures.

Notes: The number in parentheses in the above table is the standard deviation of the estimated coefficients, ${ }^{* *}, * *$, and ${ }^{*}$ indicate significant at the $1 \%, 5 \%$, and $10 \%$ levels, respectively. 
24.41 and 28.45 , respectively, both of which were significant at the $1 \%$ level, indicating that low- and medium-high government subsidies can promote enterprises conduct private $\mathrm{R} \& \mathrm{D}$ expenditure. The sample multiplier effect of the highest subsidy rate is the weakest, at 10.88, which is significant at the level of $1 \%$. This shows that when the scale of public $\mathrm{R} \& \mathrm{D}$ subsidies increases to a certain extent, it will reduce the promotion of private R \& D expenditure. High R \& $\mathrm{D}$ funds will squeeze out some of the enterprises' private $\mathrm{R} \& \mathrm{D}$ expenditure, and the company will use the funds that should be invested in $\mathrm{R} \& \mathrm{D}$ for other purposes. In summary, moderately moderate public subsidies rates can significantly promote companies to increase private R \& D expenditure, while high government subsidies rates will squeeze out private $\mathrm{R} \& \mathrm{D}$ expenditure.

\section{4. "U-Shaped" Relationship Test}

To reflect the possible nonlinear relationship between the public R \& D subsidies and the private $\mathrm{R} \& \mathrm{D}$ expenditure of enterprises, this paper adds the squared item of public R \& D subsidies to the model.

$$
\mathrm{ERD}_{i, t}=\alpha \mathrm{GRD}_{i, t}+\theta \mathrm{GRD}_{i, t}^{2}+\beta \mathrm{FL}_{i, t}+\delta \mathrm{OF}_{i, t}+\varepsilon \mathrm{EP}_{i, t}+\gamma_{i}+\epsilon_{i, t}
$$

If the coefficient $\theta$ of the squared term of publlic R \& D subsidies is significantly positive, it indicates that there is a "U-shaped" relationship between public $\mathrm{R} \& \mathrm{D}$ subsidies and private $\mathrm{R} \& \mathrm{D}$ expenditure. If the coefficient $\theta$ is significantly negative, the impact of public $\mathrm{R} \& \mathrm{D}$ subsidies on private $\mathrm{R} \& \mathrm{D}$ expenditure is shown the "inverted U-shaped" curve. And if the coefficient $\theta$ is not significant, indicates that there is no "U-shaped" or "inverted U-shaped" curve relationship between the two.

From the Stata estimation results in Table 6, it can be found that the coefficient $\theta$ is significantly positive at the level of $1 \%$, which indicates that the Guangdong Provincial Government's R \& D subsidies for industrial enterprises has an influence on the "U-shaped" curve of the enterprise's private R \& D expenditure. It differs from the "inverted U-shaped" curve that most literatures have drawn. In the group regression of the previous part, we conclude that the lower public subsidies rate has the largest multiplier effect on the private R \& D expenditure of enterprises, and the high public subsidies level has the least promotion effect on the private $\mathrm{R} \& \mathrm{D}$ expenditure of enterprises. Think of the impact of public R \& D subsidies on the private R \& D expenditure from 2006 to 2013 as a whole, which is located on the left side of the inflection point of the " $U$ " curve and is close to the inflection point. Therefore, the low subsidies rate's multiplier effect is the biggest. On the contrary, the high subsidies rate's multiplier effect is the weakest. This phenomenon may be caused by the fact that the Guangdong public R \& D subsidies for industrial enterprises is too small.

\section{The Impact of Public R \& D Subsidies on Corporate Innovation Performance}

Enterprises invest in R \& D resources for innovative production. The production 
process can be divided into two stages-the stage of knowledge output and the stage of marketization. In line with this, innovative outputs can be divided into two types-knowledge output and market return. This paper comprehensively considers the two stages of enterprise technology innovation, and uses the number of patent applications and new product sales revenue to measure the technological innovation performance of enterprises. The number of patent applications is the explained variable of the knowledge output stage, which can reflect the output of enterprise technology innovation to a certain extent; the new product sales income is the explained variable in the marketization stage, which can reflect the commercialization level and market value of enterprise technology innovation.

\subsection{Knowledge Output Stage}

The knowledge output of enterprise innovation, also called intermediate output, represents the new knowledge and new technology, this article uses the number of patent applications to represent it. The number of patent applications is used as an explained variable, and R \& D capital inputs (private R \& D expenditure, public R \& D subsidies, financial institution loans, other funds) from different sources and R \& D personnel inputs are used as explanatory variables in the linear function:

$$
\ln P_{i, t}=\beta_{1} \ln \mathrm{ERD}_{i, t}+\beta_{2} \ln \mathrm{GRD}_{i, t}+\gamma \ln L_{i, t}+\delta_{1} \ln \mathrm{FL}_{i, t}+\delta_{2} \ln \mathrm{OF}_{i, t}+\epsilon_{i, t}
$$

Table 7 shows the results of regression analysis on the above model.

\subsubsection{Comparative Analysis of FE and RE}

The fixed effects analysis results using the stata12.0 software showed (F test that

Table 7. Impact of public R \& D subsidies on innovation performance of enterprises in the stage of knowledge output.

\begin{tabular}{|c|c|c|c|c|}
\hline Variable & OLS & FE & $\mathrm{RE}$ & MLE \\
\hline LnERD & $\begin{array}{c}0.312 \\
(0.224)\end{array}$ & $\begin{array}{c}0.279 \\
(0.251)\end{array}$ & $\begin{array}{c}0.312 \\
(0.224)\end{array}$ & $\begin{array}{c}0.314 \\
(0.215)\end{array}$ \\
\hline LnGRD & $\begin{array}{l}0.370^{\star * *} \\
(0.134)\end{array}$ & $\begin{array}{l}0.416^{\star *} \\
(0.180)\end{array}$ & $\begin{array}{c}0.370^{\star * *} \\
(0.134)\end{array}$ & $\begin{array}{c}0.366^{\star * *} \\
(0.129)\end{array}$ \\
\hline $\operatorname{Ln} L$ & $\begin{array}{c}0.426^{\star * *} \\
(0.154)\end{array}$ & $\begin{array}{l}0.381^{\star *} \\
(0.177)\end{array}$ & $\begin{array}{c}0.426^{\star * *} \\
(0.154)\end{array}$ & $\begin{array}{l}0.431^{\star * \star} \\
(0.150)\end{array}$ \\
\hline LnFL & $\begin{array}{l}-0.102^{\star *} \\
(0.0490)\end{array}$ & $\begin{array}{l}-0.116^{* *} \\
(0.0545)\end{array}$ & $\begin{array}{l}-0.102^{\star *} \\
(0.0490)\end{array}$ & $\begin{array}{l}-0.100^{\star *} \\
(0.0475)\end{array}$ \\
\hline LnOF & $\begin{array}{c}-2.09 \mathrm{e}-05 \\
(0.0366)\end{array}$ & $\begin{array}{l}0.00641 \\
(0.0389)\end{array}$ & $\begin{array}{c}-2.09 \mathrm{e}-05 \\
(0.0366)\end{array}$ & $\begin{array}{c}-0.000585 \\
(0.0355)\end{array}$ \\
\hline Constant & $\begin{array}{c}-2.895^{\star \star} \\
(1.180)\end{array}$ & $\begin{array}{l}-2.373 \\
(1.447)\end{array}$ & $\begin{array}{c}-2.895^{\star \star} \\
(1.180)\end{array}$ & $\begin{array}{c}-2.920^{* *} \\
(1.136)\end{array}$ \\
\hline R-squared & - & 0.774 & - & - \\
\hline $\mathrm{F}$ & - & 41.79 & - & - \\
\hline Sum of elastic coefficients & 1.0059791 & 0.96641 & 1.0059791 & 1.010415 \\
\hline
\end{tabular}

Notes: The number in parentheses in the above table is the standard deviation of the estimated coefficients, ${ }^{* * *},{ }^{* *}$, and ${ }^{*}$ indicate significant at the $1 \%, 5 \%$, and $10 \%$ levels, respectively. 
all $\mathrm{u} \_\mathrm{i}=0: \mathrm{F}(14,61)=9.55$, Prob $\left.>\mathrm{F}=0.0000\right)$, which significantly rejected the null hypothesis that each sample did not have its own intercept term. Therefore, we can preliminarily judge that every individual has different intercept terms, and the fixed effects model is superior to the ordinary least squares regression model.

\subsubsection{Hausman Test}

In this paper, the Hausman test is used to compare the fixed effect model and the random effects model. The null hypothesis of the Hausman test is to use a random effects model. The results of the Hausman test: $P$ value (Prob $>$ chi $2=$ 0.7639) accepts the null hypothesis that the random effects model should be used, so it is more reasonable to use the random effects model.

Since the results of RE and OLS are the same, the maximum likelihood method is used to estimate the random effects model, and the result is the MLE of Table 7 .

\subsubsection{Analysis of Regression Results}

According to the random effects regression results of maximum likelihood estimation, the enterprise's private R \& D expenditure is positively correlated with the patent output, but the result is not significant. The public R \& D subsidies can significantly promote the increase of the number of patent applications, indicating that the public subsidies have an incentive effect on enterprises' innovation performance in the stage of knowledge output. The other two sources of funding-financial institution loans and overseas funds are negatively correlated with enterprises' innovation output. This may be related to the repayment pressure of loans from other sources. Enterprises are not willing to use this part of the loan for R \& D innovation.

The input of $\mathrm{R} \& \mathrm{D}$ personnel has a very significant role in promoting the patent output of enterprises, and its multiplier effect is the largest. As a technology-intensive activity, patent production is a process of creating new knowledge. It requires high-quality talents with high knowledge reserves and mastery of professional skills. Therefore, the increase in $\mathrm{R} \& \mathrm{D}$ personnel investment can significantly promote the number of patent applications. It shows the importance of cultivating scientific and technological talents for R \& D and innovation. In general, the sum of the elasticity coefficients of Guangdong's industrial enterprises' investment in patent output is about equal to 1 , showing the trend of constant return on patent output.

\subsection{Marketization Stage}

The market gains from the production of innovations as new products are called final outputs and represent the level of commercialization of innovations. This part takes the sales income of new products of industrial enterprises as the explanatory variables, and the other variables are unchanged, and the following model is obtained. 


$$
\ln Y_{i, t}=\beta_{1} \ln \mathrm{ERD}_{i, t}+\beta_{2} \ln \mathrm{GRD}_{i, t}+\gamma \ln L_{i, t}+\delta_{1} \ln \mathrm{FL}_{i, t}+\delta_{2} \ln \mathrm{OF}_{i, t}+\epsilon_{i, t}
$$

Table 8 shows the results of regression analysis on the above model.

\subsubsection{Comparative Analysis of FE and RE}

The results of fixed effects analysis using stata12.0 software showed (F test that all $\mathrm{u} \_\mathrm{i}=0: \mathrm{F}(14,61)=7.77$ Prob $\left.>\mathrm{F}=0.0000\right)$, which significantly rejected the null hypothesis that each sample does not have its own intercept term, so we can preliminarily judge that every individual has different intercept terms, and the fixed effects model is better than the ordinary least squares regression model.

\subsubsection{Hausman Test}

The Hausman test is used to compare the fixed effects model and the random effects model. The null hypothesis of the Hausman test is to use a random effects model. The results of the Hausman test show that the $P$ value (Prob $>$ chi $2=$ 0.3746 ) is significantly greater than 0.05 , and the null hypothesis that the random effects model should be used is accepted, so it is more reasonable to use the random effects model.

\subsubsection{Analysis of Regression Results}

In the commercialization stage of innovation results, the private R \& D expenditure of enterprises has a significant promotion effect on the sales revenue of new products, indicating that the private $\mathrm{R} \& \mathrm{D}$ expenditure of enterprises can directly increase the sales revenue of new products of enterprises; while the public

Table 8. Impact of government R \& D subsidies on corporate innovation performance in the marketization stage.

\begin{tabular}{ccccc}
\hline Variable & OLS & FE & RE & MLE \\
\hline LnERD & $1.162^{* * *}$ & $1.079^{* * *}$ & $1.162^{* * *}$ & $1.166^{* * *}$ \\
& $(0.175)$ & $(0.196)$ & $(0.175)$ & $(0.171)$ \\
LnGRD & $-0.242^{* *}$ & -0.0654 & $-0.242^{* *}$ & $-0.245^{* *}$ \\
& $(0.102)$ & $(0.140)$ & $(0.102)$ & $(0.103)$ \\
LnL & 0.191 & 0.110 & 0.191 & 0.191 \\
& $(0.121)$ & $(0.138)$ & $(0.121)$ & $(0.117)$ \\
LnFL & $-0.0936^{* *}$ & $-0.126^{* * *}$ & $-0.0936^{* *}$ & $-0.0928^{* *}$ \\
& $(0.0385)$ & $(0.0426)$ & $(0.0385)$ & $(0.0378)$ \\
LnOF & 0.0261 & 0.0158 & 0.0261 & 0.0262 \\
& $(0.0290)$ & $(0.0304)$ & $(0.0290)$ & $(0.0280)$ \\
Constant & 1.448 & $1.966^{*}$ & 1.448 & 1.423 \\
R-squared & $(0.908)$ & $(1.131)$ & $(0.908)$ & $(0.903)$ \\
F & & 0.838 & & \\
Sum of elastic coefficients & 1.0435 & 1.0134 & 1.0435 & \\
\hline
\end{tabular}

Notes: The number in parentheses in the above table is the standard deviation of the estimated coefficients, $* * *, * *$ and ${ }^{*}$ indicate significant at the $1 \%, 5 \%$, and $10 \%$ levels, respectively. 
R \& D subsidies show a significant negative effect. It shows that public subsidies have not played a role in the commercialization stage. It may because that this part of the subsidies is used by enterprises for patent production. This also reflects the fact that the total investment in $\mathrm{R} \& \mathrm{D}$ of industrial enterprises by the Guangdong provincial government is still not large enough. Loans from financial institutions have not been able to promote an increase in sales revenue, and overseas funds have not shown a significant boost. It shows that the enterprise mainly uses the funds of the enterprise itself in the commercialization stage, and the subsidies from other sources have not played a significant role at this stage. Although both government and enterprise have the incentive to increase $\mathrm{R} \& \mathrm{D}$ investment, their motivations are not the same. The government's increased R \& D investment in enterprises is mainly to activate R \& D activities of enterprises to promote technological progress and social progress. Therefore, the impact of policy tools on R \& D output is indirect. As the main force of R \& D investment, enterprises' purpose of innovation is to gain competitive advantage in the market and obtain high profits. It is the direct beneficiary of the marketization stage, and it will try to improve the efficiency and quality of R \& D output.

In addition, the human resource factor is different from the knowledge output stage. The input of enterprise $\mathrm{R} \& \mathrm{D}$ personnel has a positive impact on sales revenue, but the result is not significant. The reason may be that compared with patent production, new product sales is the process of industrializing patents. In this link, the increase in sales revenue has little to do with the input of R \& D personnel, mainly relying on the marketing of enterprises to increase revenue. However, the number of patents is significantly and positively related to the input of R \& D personnel, so the input of R \& D personnel has an indirect but not significant promotion effect on the sales revenue of new products.

\section{Conclusions and Suggestions}

\subsection{Conclusions}

Through empirical analysis, the paper draws the following conclusions:

The influence of $\mathrm{R} \& \mathrm{D}$ funds from different channels on the private $\mathrm{R} \& \mathrm{D}$ expenditure of enterprises is different: public $\mathrm{R} \& \mathrm{D}$ subsidies have significant incentive effect, loans from financial institutions have no obvious effect, and overseas funds have negative effect on private R \& D expenditure. However, in the long run, R \& D subsidies obtained from three different channels can promote enterprises to increase $\mathrm{R} \& \mathrm{D}$ expenditures, which may be due to the lag effect caused by the availability of funds. Among them, the public R \& D subsidies have a strong time lag on the incentive effect of independent R \& D expenditure, indicating that it takes time for the public subsidies to be implemented in industrial enterprises; there is a time difference between them. Therefore, the leverage effect brought by public subsidies to enterprises needs time to reflect. One 
phase of government subsidies can continue to stimulate the private R \& D expenditure of enterprises.

Through group regression, the medium-low and medium-high public subsidies rates have the most significant incentive effect on private $\mathrm{R} \& \mathrm{D}$ expenditure. The lower public subsidies have the largest multiplier effect, while the high government subsidies often squeeze out some of the enterprises' private R \& D expenditure. By adding the squared item of public R \& D subsidies to the model, there is a U-shaped relationship between public subsidies and private R \& D expenditures. This paper speculates that the impact of public $\mathrm{R} \& \mathrm{D}$ subsidies on private $\mathrm{R} \& \mathrm{D}$ expenditures in Guangdong may be on the left side of the $\mathrm{U}$-shaped curve, and is about to approach the inflection point, indicating that the public $\mathrm{R} \& \mathrm{D}$ subsidies policy for industrial enterprises is not mature enough compared to the foreign subsidies policy, and the total subsidies are not large enough.

To study the impact of government R \& D investment on corporate innovation performance, this paper divides the innovation results into two stages: knowledge output and marketization. In the knowledge output stage, public R \& $\mathrm{D}$ subsidies can significantly promote the increase in the number of patent applications, while financial institution loans and overseas funds are negatively correlated with corporate innovation output. R \& D personnel's input has a significant role in promoting corporate patent output; its multiplier effect is the biggest. In the marketization stage, the private $\mathrm{R} \& \mathrm{D}$ expenditures have a significant effect on the sales revenue of new products, while the government $\mathrm{R} \& \mathrm{D}$ subsidies have shown a significant negative effect. Funds from other sources have not played a significant role at this stage. Meanwhile, enterprise R \& D personnel has a positive impact on the sales revenue of new products, but the results are not significant.

\subsection{Suggestions}

Therefore, the government should continue to increase public R \& D subsidies in industrial enterprises, and continue to adopt various means to guide all sectors of society to invest in R \& D and increase the total amount and intensity of R \& D funding. For example, the government should create a good investment and financing environment, provide more financing channels for enterprises, and make full use of foreign capital to induce enterprises to increase their private $\mathrm{R} \& \mathrm{D}$ expenditure. Utilizing the time lag of $\mathrm{R} \& \mathrm{D}$ investment, long-term continuous investment will certainly promote the company's ability to innovate.

This paper believes that the government should increase the R \& D subsidies in industrial enterprises, but it should be gradual and avoid excessively high subsidies intensity to crowd out the private $\mathrm{R} \& \mathrm{D}$ expenditures. It is hoped that by strengthening the overall $\mathrm{R} \& \mathrm{D}$ subsidies intensity, Guangdong industrial enterprises can smoothly pass the inflection point of the "U-shaped" curve. 
For the industrial enterprises, in the knowledge output stage, the input of R \& $\mathrm{D}$ personnel should be increased, and R \& D personnel training should be emphasized, and more R \& D personnel should be provided to the enterprises, so as to improve the efficiency of innovation and obtain more patented products. As an intermediate output of enterprise innovation, patent output can help enterprises produce more competitive new products, so that enterprises can profit in the market stage. Although $\mathrm{R} \& \mathrm{D}$ personnel's contribution to innovation performance is not significant in the marketization stage, the intermediate role cannot be ignored. Therefore, the government should increase R \& D subsidies in universities and $\mathrm{R} \& \mathrm{D}$ institutions, train and select $\mathrm{R} \& \mathrm{D}$ personnel, and encourage highly educated personnel to engage in innovation. Marketization is the advantage of Guangdong's economic development, and it is also the key to motivating enterprises to increase investment in research and development. Therefore, it is necessary to give play to the advantages of marketization, form a mechanism to accelerate the transformation of scientific and technological achievements into real productivity, and then promote the accumulation of scientific and technological resources, promote enterprises to continue technological innovation, and fully exert the role of market allocation of scientific and technological resources.

\subsection{Forecast}

Huang Qunhui, director of the Institute of Industrial Economics of the Chinese Academy of Social Sciences, said: "The trade disputes between China and US remind us that the need to promote the transformation and upgrading of China's manufacturing industry." Technological innovation is the internal driving force for the transformation and upgrading of industrial industries. In "Made in China 2025", seven cities including Guangzhou, Foshan, Zhongshan and Zhuhai in Guangdong Province will be used as technology demonstration cities. In the future, the government will continue to increase the emphasis on industrial innovation in these places. Based on the government's continuous increase in R \& $\mathrm{D}$ investment, the enterprises should also actively increase investment in research and development, make full use of the resources provided by the government. In this way, we can jointly promote the original innovation of industrial enterprises in Guangdong Province, accelerate the transformation of scientific and technological achievements, improve the driving force for innovation, and let technological innovation drive development even better.

\section{Acknowledgements}

Campus time is always fleeting, and the journey of graduate students is not just me alone. Thanks to the family who always accompany me, you are my strongest backing. The research road is rugged, and I am grateful to my tutor, Associate Professor Jingwen Xia, for guiding me through me, so that I can continue to improve. Thanks to the help of my classmates in the learning process, you are the 
most precious harvest of my postgraduate stage. In the future, I hope that everyone will help each other and work together.

\section{Conflicts of Interest}

The authors declare no conflicts of interest regarding the publication of this paper.

\section{References}

[1] Solow, R.M.A. (1956) Contribution to the Theory of Economic Growth. The Quarterly Journal of Economics, 70, 65-94. https://doi.org/10.2307/1884513

[2] Lach, S. (2002) Do R\&D Subsidies Stimulate or Displace Private R\&D? Evidence from Israel. Journal of Industrial Economics, 50, 369-390.

https://doi.org/10.1111/1467-6451.00182

[3] Guellec. D. and Van Pottelsberghe, B. (2000) The Impact of Public R\&D Expenditure on Business R\&D. OECD STI Working Papers, 4.

[4] Marino, M., Lhuillery, S., Parrotta, P. and Sala, D. (2016) Additionality or Crowding-Out? An Overall Evaluation of Public R\&D Subsidy on Private R\&D Expenditure. Research Policy, 45, 1715-1730. https://doi.org/10.1016/j.respol.2016.04.009

[5] Lu, J.Q. and Yu, D.D. (2011) Government Research and Innovation Subsidies and Enterprise R\&D Investment: Extrusion, Substitution or Incentive? China Science and Technology Forum, 8, 21-28.

[6] Yang, W., Wang, P., Li, Y.H. and Yang, D.Z. (2015) Research on the Impact of Financial Subsidy on R\&D Investment and Performance of Enterprises-Evidence from Chinese GEM Listed Companies. Journal of Finance and Economics, 1, 24-31.

[7] Zhang, J., Chen, Z.Y., Yang, L.X. and Xin, F. (2015) Performance Evaluation of China's Innovation Subsidy Policy: Theory and Evidence. Economic Research, 10, 4-17.

[8] Almus, M. and Czarnitzki, D. (2003) The Effects of Public R\&D Subsidies on Firms' Innovation Activities: The Case of Eastern Germany. Journal of Business \& Economic Statistics, 21, 226-236. https://doi.org/10.1198/073500103288618918

[9] Liu, X.L., Li, X.Y. and Li, H.L. (2016) R\&D Subsidies and Business R\&D: Evidence from High-Tech Manufacturing Firms in Jiangsu. China Economic Review, 41, 1-22. https://doi.org/10.1016/j.chieco.2016.08.003

[10] Sun, Z. and Song, W. (2012) The Impact of Enterprise R\&D Investment on Industrial Innovation Performance: Empirical Evidence from Chinese Manufacturing Industry. Quantitative Economics and Technology Economics Research, 4, 49-63.

[11] Lu, G.Q., Wang, Z. and Zhang, C.Y. (2014) Performance Research on Government Innovation Subsidies in China's Strategic Emerging Industries. Economic Research, 7, 44-55.

[12] Wang, J. (2011) Comparison of Output Efficiency between Government R\&D Funding and Enterprise R\&D Investment. Quantities Economics and Technology Research, 6, 93-106.

[13] An, T.L., Zhou, S.D. and Pe, J.C. (2009) Incentive Effect of R\&D Subsidy on Independent Innovation of Chinese Enterprises. Economic Research, 10, 87-98.

[14] An, T.L., Shi, H. and Alcorta, L. (2006) Observation and Empirical Study of R\&D Behavior Models of Chinese Manufacturing Enterprises-An Empirical Analysis 
Based on Questionnaire Survey of Manufacturing Enterprises in Jiangsu Province. Economic Research, 2, 69-73.

[15] Liu, H., Xiao, M.F. and Tang, Q.Q. (2012) Incentive and Extrusion Effect of R\&D Subsidy on Enterprise R\&D Expenditure-An Empirical Analysis Based on Data of Chinese Listed Companies. Economic Management, 4, 19-28. 